Supporting Information for:

\title{
Comprehensive Molecular Compositions and Origins of DB301 Crude Oil from Deep Strata, Tarim Basin, China
}

\author{
Meng Wang ${ }^{1}$, Guangyou Zhu ${ }^{1 *}$, Alexei V. Milkov², Linxian $\mathrm{Chi}^{3}$ \\ ${ }^{1}$ Research Institute of Petroleum Exploration and Development, PetroChina, Beijing \\ 100083, China \\ ${ }^{2}$ Colorado School of Mines, Golden, Colorado 80401, USA \\ ${ }^{3}$ China University of Geosciences, Beijing 100083, China \\ *Corresponding Author: zhuguangyou@petrochina.com.cn
}




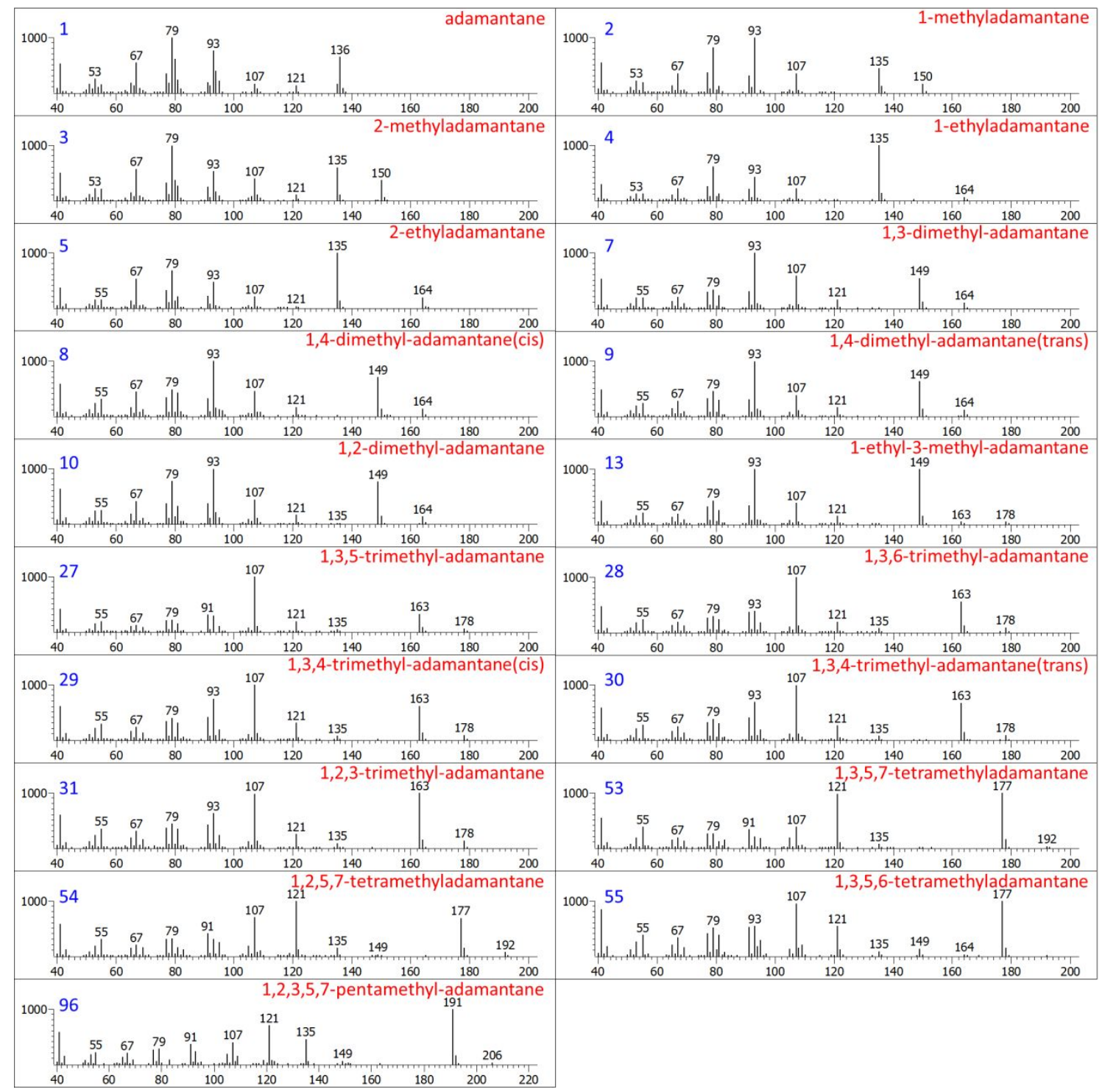

Figure S-1. Mass spectra of adamantanes No. 1 10, 13, 27 31, 53 55 and 96 in Table 3. 


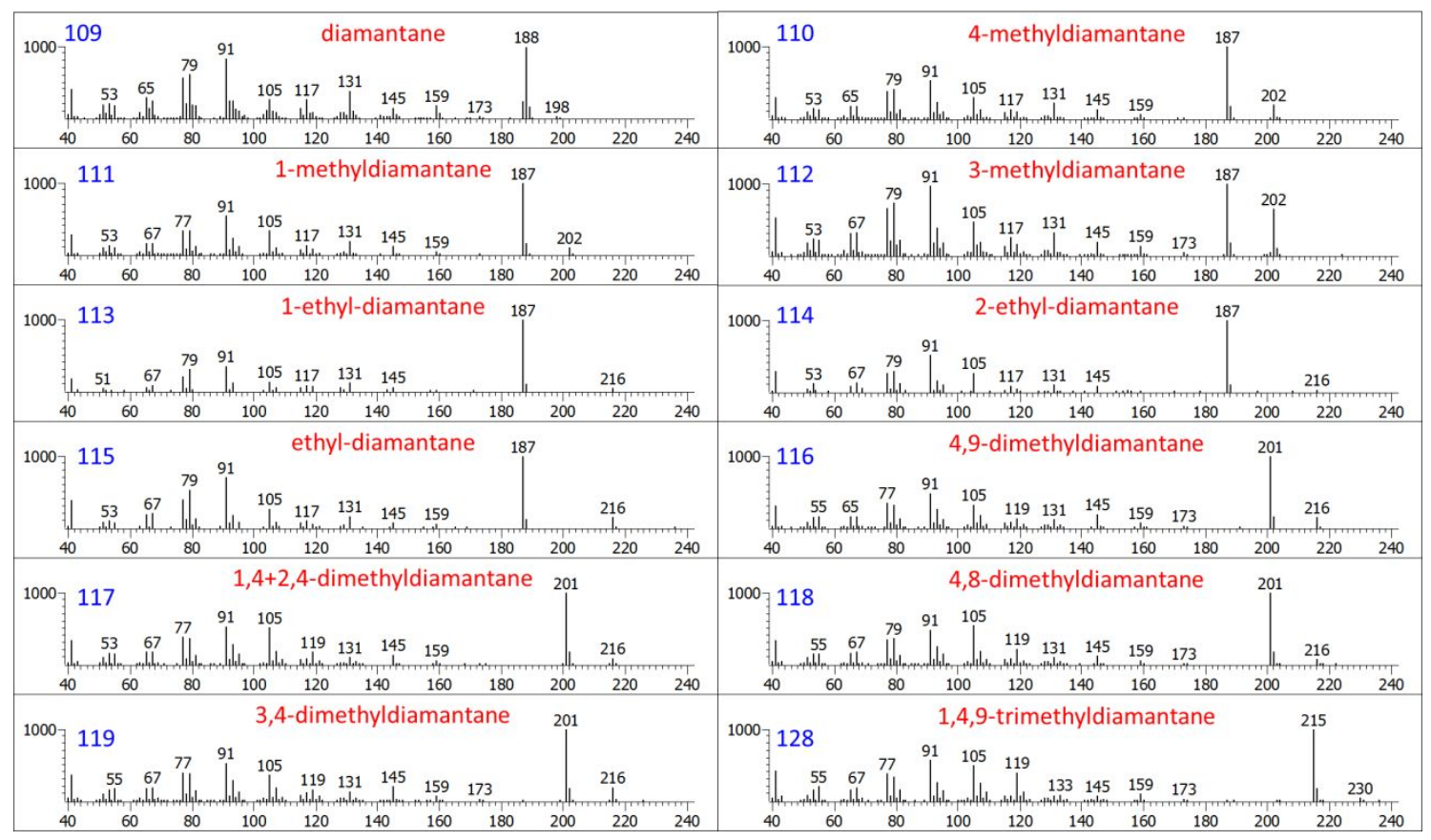

Figure S-2. Mass spectra of diamantanes No. 109 119 and 128 in Table 3. 


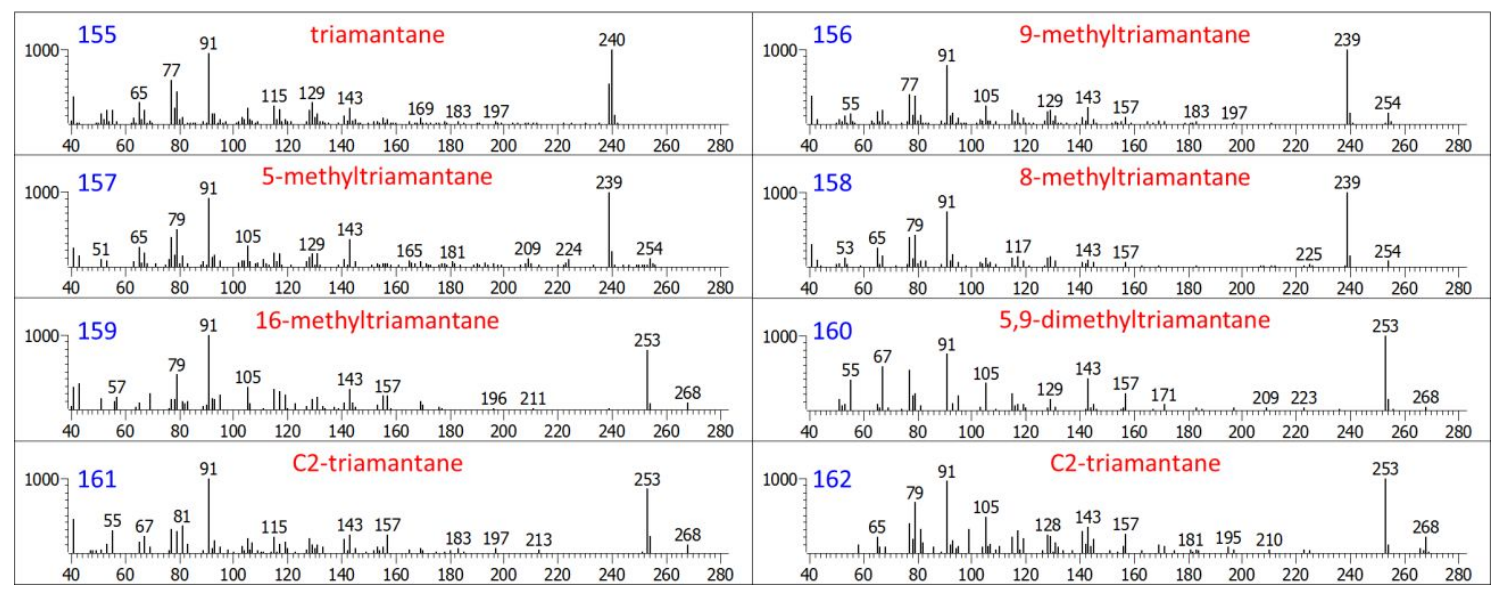

Figure S-3. Mass spectra of triamantanes No. 155 162 in Table 3. 


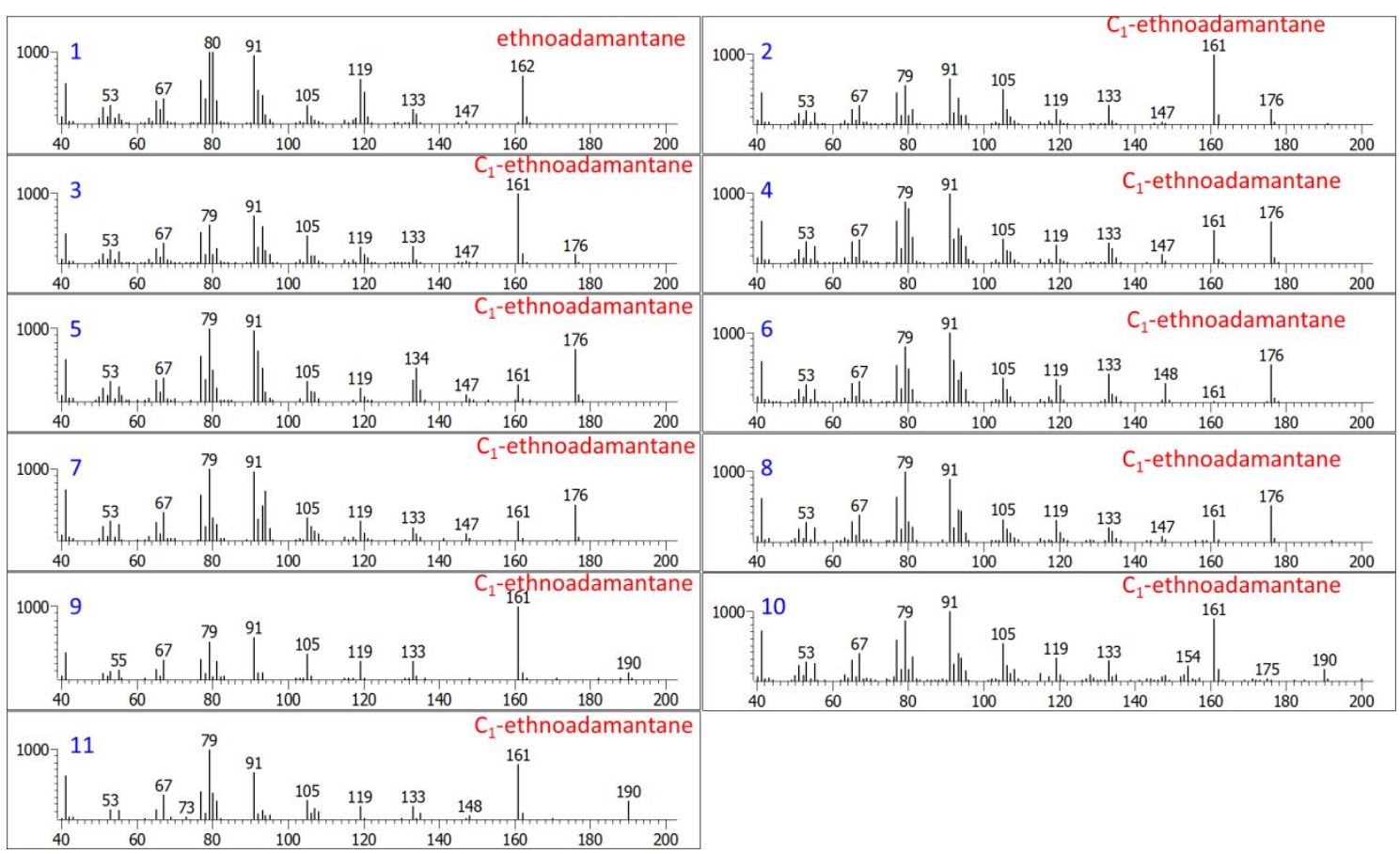

Figure S-4. Mass spectra of ethanoadamantanes No. 1 11 in Table 4. 


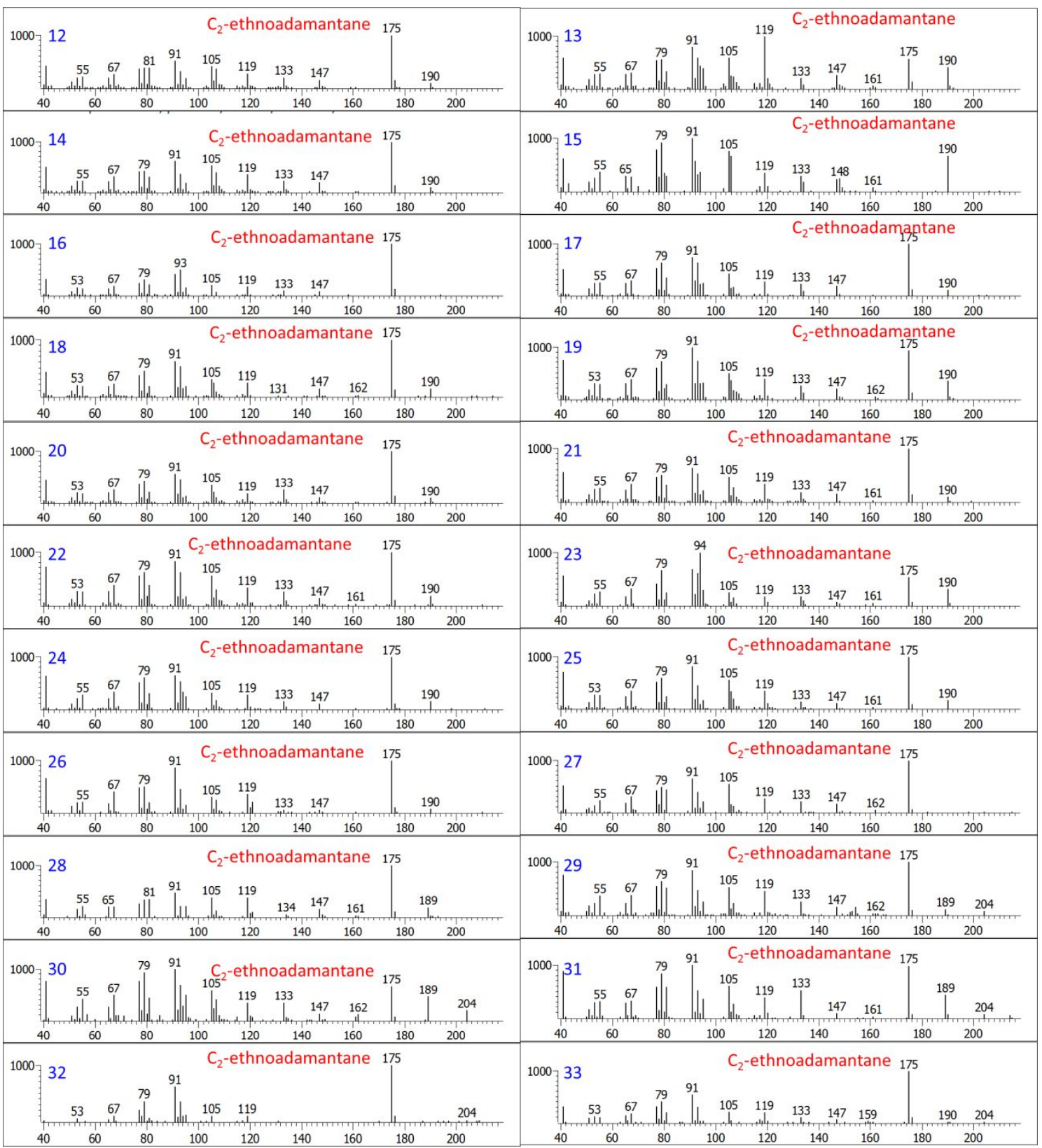

Figure S-5. Mass spectra of ethanoadamantanes No. 12 33 in Table 4. 


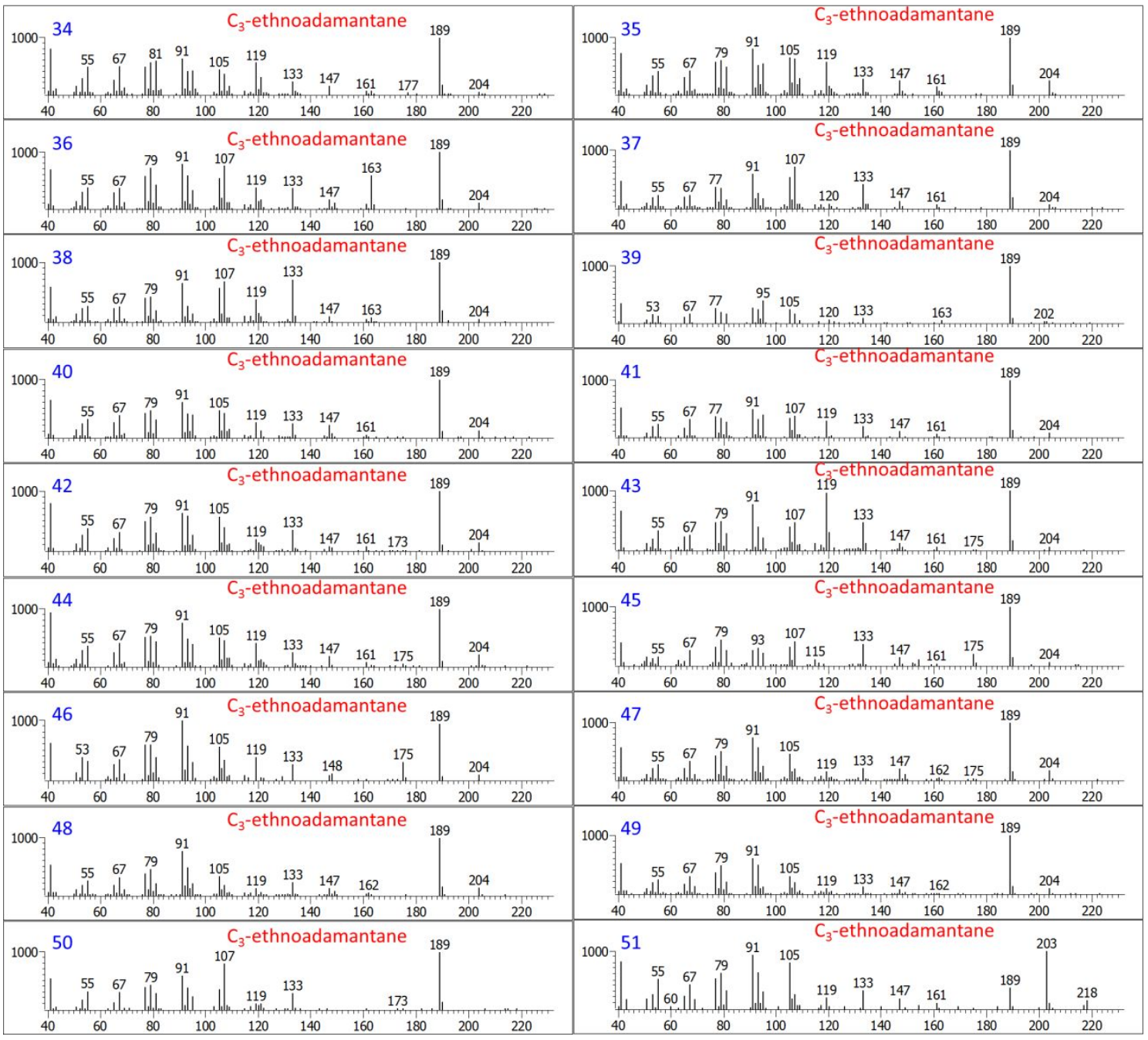

Figure S-6. Mass spectra of ethanoadamantanes No. 34 51 in Table 4. 


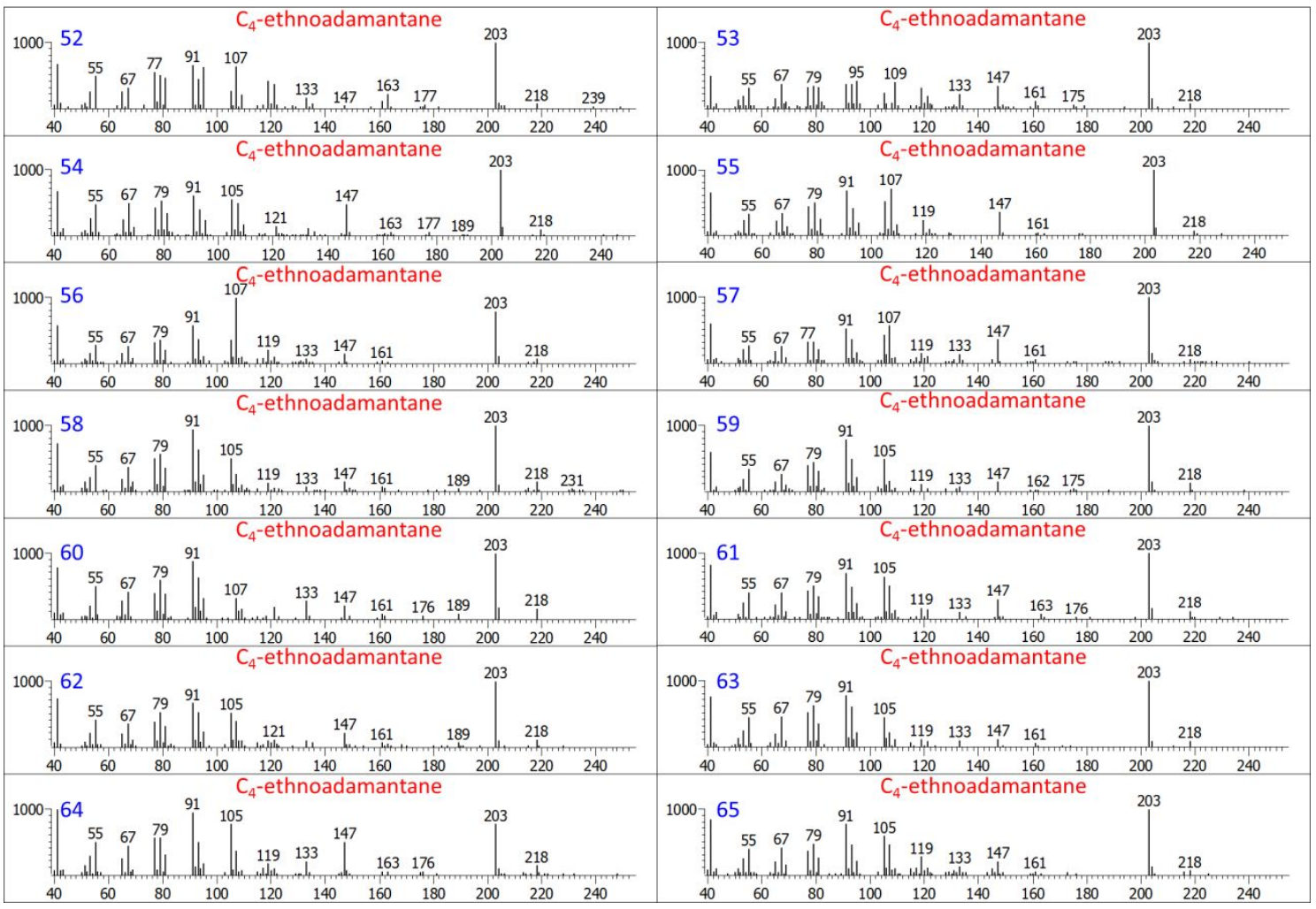

Figure S-7. Mass spectra of ethanoadamantanes No. 52 65 in Table 4. 


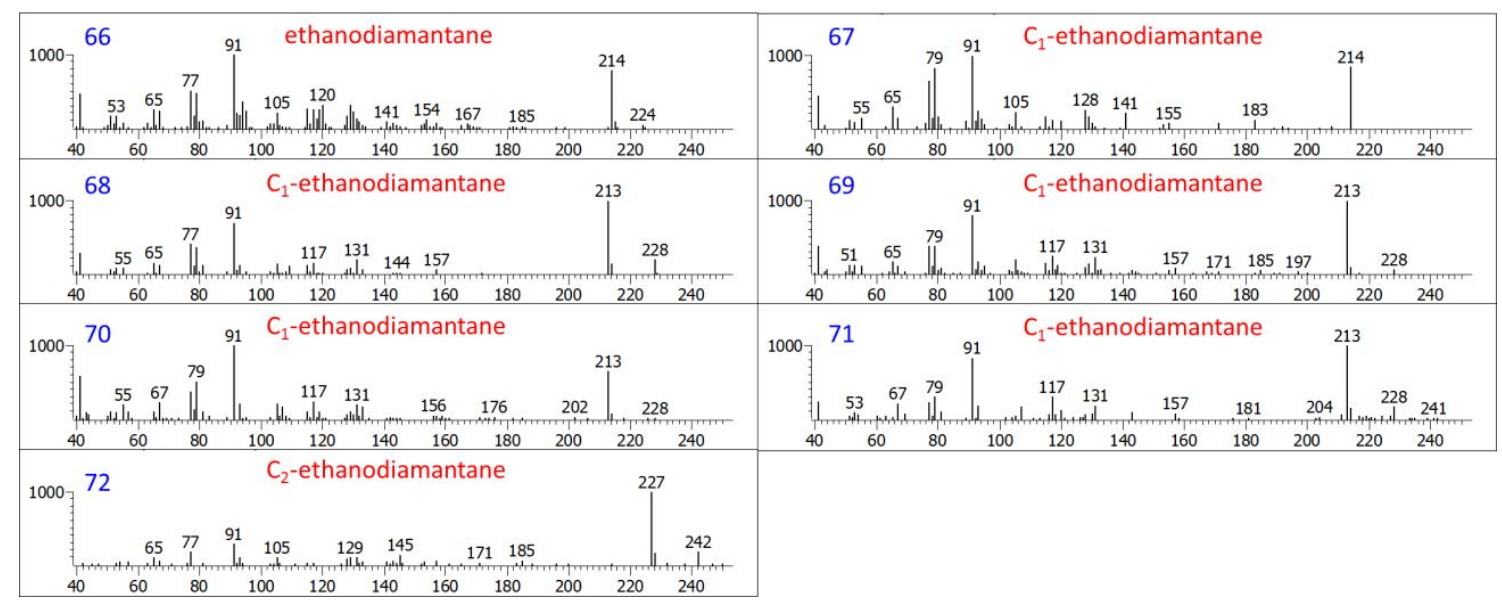

Figure S-8. Mass spectra of ethanodiamantanes No. 66 72 in Table 4. 